\title{
WIN, WIN, WIN: THE ENGINEER IN RESIDENCE PROGRAM AT OHIO NORTHERN UNIVERSITY.
}

\author{
Barry Farbrother ${ }^{1}$, Kevin Stoodt ${ }^{2}$, Brad Crombie ${ }^{3}$, Ryan Korkos ${ }^{4}$, \\ Matt Launsbach ${ }^{5}$, Jacqui Wagner ${ }^{6}$, Katie Zwingler ${ }^{7}$.
}

A collaborative effort between the T.J. Smull College of Engineering at Ohio Northern University (ONU), and Marathon Ashland Petroleum LLC (MAP) provides benefits for the corporation, the university and for students. The program provides an office within the college of engineering from which a practicing professional - the Engineer in Residence - operates. The Engineer-in-Residence is an employee of MAP, not ONU. The EiR office space is leased under an annual contract, which includes the provision of some support services - utilities, housekeeping, LAN/www, telephone and security - plus 24/7 access to the Biggs Engineering building. The facility is a scaled-down professional office providing a dedicated space for the EiR, and several engineering cubicles for use by college of engineering undergraduate students. Each station contains a computer workstation, which is linked to the ONU LAN thereby enabling students to gain access to MAP's LAN. Currently engineering students are working on more than fifty projects under the direction of the EiR. The program provides students with opportunities to work on real world projects in an environment that parallels the workplace. The agreement also provides a mechanism whereby college of engineering faculty members may invite the EiR to participate in class activities. For up to 15 hours per academic quarter the EiR may be called upon to address workplace-related issues, thereby providing students with a better preparation for professional practice. Example topics include engineering standards, economic, environmental, sustainability, manufacturability, ethical, health and safety, social, and political issues. This paper describes the program, includes comment from the Engineer in Residence, undergraduate students, and the dean of engineering at Ohio Northern University.

Index Terms — Professional practice, Co-operative education, Experiential work, and Innovative program.

\section{INTRODUCTION}

The Engineer in Residence (EiR) program is a unique collaborative effort between Marathon Ashland Petroleum LLC (MAP) and Ohio Northern University (ONU). For a typical co-op session a student has to take time off from their college education to perform a co-op at a company's facility. The EiR program is designed to allow engineering students to work 10 to 15 hours a week in an engineering office environment while taking classes on campus. Balancing school work while working an additional 10 to 15 hours in the office presents a challenge, but it is an excellent opportunity to gain work experience for those students still looking to graduate in four years.

Kevin Stoodt, the 2003-2004 Engineer in Residence and a 2001 mechanical engineering graduate of the University of Dayton, is employed by MAP. As the EiR, Stoodt typically

\footnotetext{
${ }^{1}$ B. J. Farbrother Ph.D., C.Eng. Dean, Thomas Jefferson Smull College of Engineering, Ohio Northern University, Ada, Ohio 45810, USA. b-farbrother@onu.edu

${ }^{2}$ K. R. Stoodt, BSME, Engineer in Residence, Biggs Engineering Building, 525 South Main Street, Ada, OH 45810, USA. krstoodt@mapllc.com

${ }^{3}$ B. L. Crombie, CE Undergraduate, Unit 2250, 525 South Main Street, Ada, OH 45810, USA. b-crombie@onu.edu

${ }^{4}$ R. M. Korkos, EE Undergraduate, Unit 2662, 525 South Main Street, Ada, OH 45810, USA. r-korkos@onu.edu

${ }^{5}$ M. S. Launsbach, ME Undergraduate, Unit 2426, 525 South Main Street, Ada, OH 45810, USA. m-launsbach@onu.edu

6 J. T. Wagner, EE Undergraduate, 525 South Main Street, Ada, OH 45810, USA. j-wagner@onu.edu

${ }^{7}$ K. J. Zwingler, ME Undergraduate, Unit 3594, 525 South Main Street, Ada, OH 45810, USA. k-zwingler@onu.edu
} 
works two to three days a week in the EiR office at ONU and the remaining time at MAP's headquarters located in Findlay, Ohio.

The EiR serves two functions. The first is as a supervisor, handing out assignments and keeping track of the progress of those projects. The EiR also functions as a mentortraining, explaining and instructing the students about MAP, job responsibilities, and answering questions.

The EiR also serves as a resource to ONU. As a part of the agreement between MAP and ONU, the EiR may be called upon for up to 15 hours every academic quarter to address workplace related issues such as ethics, standards, scheduling, economics, health, safety, and other engineering workplace topics. Having the EiR speak about topics in the classroom helps the students understand real-world issues.

The Engineer in Residence office, located in the Biggs Engineering building, is a space leased under an annual contract. As a part of the contract, some services are included, such as utilities, housekeeping, telephone, security, and access to the Biggs Engineering building. LAN access is also provided as a part of the contract, but MAP installed a DSL line to improve some of the problems related with the ONU and MAP networks "crosstalking".

Currently, the EiR office employs five students; two electrical engineers (Ryan Korkos and Jacqui Wagner), two mechanical engineers (Matt Launsbach and Katie Zwingler), and one civil engineer (Brad Crombie). The work the students perform is delegated by MAP engineers to the EiR who assigns the work, taking into consideration the due date, knowledge needed to perform the work, and current student work load, as needed. Typically the work is a project that is important to the company, but has a less demanding deadline, allowing a person working limited hours to complete it on time.

\section{COMMENTS BY THE ENGINEER IN RESIDENCE}

The EiR program has been a win-win-win situation. The program provides MAP an extra resource to help get projects completed. Most of the projects are design related and having the office in Ada allows students to obtain assistance from professors when needed. The EiR office also provides MAP an additional recruiting resource. The EiR program allows MAP to recruit students who usually would not be involved in a typical co-op program. MAP is able to evaluate the work performed by the student before he or she receives a full-time offer.

The EiR program benefits ONU because it establishes a strong tie to a leader in the petroleum industry. The EiR program also helps support the ONU engineering accreditation status and provides the University with another student recruiting tool.

The students win by having the chance to gain engineering experience in real-world situations. The students also gain experience on managing their school work, social life, 
and work schedule. The students also benefit by earning a good salary to help pay for their educational expenses.

\section{COMMENTS BY STUDENTS}

\section{Brad Crombie: Senior Civil Engineering student at Ohio Northern University.}

I have a strong interest in structural engineering and have been able to work for MAP and apply what I have learned in my structural engineering courses. I have gained irreplaceable experience working for MAP while taking a full course load in pursing my undergraduate degree.

The structural engineering project I am currently working on is verifying the structural design of both brick and block convenience store buildings. Verifying building calculations associated with this project rely heavily on a thorough understanding of both Structures I and II. I am able to directly apply what I have learned in the classroom to proposed convenience store structures. The design strength of the buildings' roof systems, walls, and footings is calculated based upon the appropriate dead, live, snow, seismic, and wind loads. The design strength must be strong enough to satisfy all building codes.

Another Structural Engineering project I worked on was rewriting the Steel Specifications for MAP and Speedway SuperAmerica convenience stores and travel centers. These specifications were written to meet the American Institute of Steel Construction (AISC) specifications for structural steel. I was able to directly apply what I have learned in the Steel Design course including use of the Manual of Steel Construction that was required for that course.

The experience, knowledge, and professionalism I have gained and developed through the Engineer-in-Residence program have been remarkable. At times I have found managing schedules between work and school demanding, but believe this has dramatically improved my time management skills. I believe this program has prepared me to continue my work as a Civil Engineer after I graduate.

Jacqui Wagner: Senior Electrical Engineering student at Ohio Northern University.

I am a full time Senior Electrical Engineering student at Ohio Northern University and work as a part time Co-op for Marathon Ashland Petroleum LLC (MAP) in the ONU Engineer in Residence (EiR) Office. This is a unique opportunity which brings the workplace to the student. I will be able to complete engineering coursework in four years and obtain related work experience at the same time.

As a student working for MAP, I have been able to work on a variety of projects and have interacted with a variety of people. My first project was to work on options for upgrading the company's current site manager equipment which is the lighting and fueling controller at convenience stores. I had the opportunity to meet and work with 
practicing engineers, purchasing departments, suppliers, and manufacturers. This project helped me sharpen my communication skills when dealing with technical aspects, which is something that is difficult to teach in a classroom.

Also, I have visited the Findlay office to meet practicing engineers and observe the work that they do on a daily basis. This is a great way to learn what the "real world" will be like when I graduate this spring.

Overall, my experience with the EiR program has been wonderful. This program has given me the chance to learn in ways that cannot be taught in a classroom setting. I have been able to apply knowledge from the classroom, improve my time management skills, and better my team work abilities. I would encourage any student to join this program if they had the chance.

\section{Katie Zwingler: Junior Mechanical Engineering student at Ohio Northern University.}

I am a full-time student attending a full schedule of classes, but I work an average of fifteen hours a week in the EiR program. The experience thus far has been beneficial to me. I have been assigned different projects relating to my field of study. For each project, I have worked with a practicing engineer who has acted as my mentor for the project. My projects have given me the opportunity to take what I have learned in the classroom and apply it to real-life situations.

The first project I worked on was a Retail Permit Response Database. The actual database had already been created, so my task was to provide information on how to open, view and revise the database through a Retail Standard. This involved first creating a flow chart describing the process of entering new information. A Standard was then written providing universal guidance regarding the database. I was completely unfamiliar with the program in which the database was created, so this project allowed me to learn a program I may not have had an opportunity to learn otherwise.

Another project that I have been working on involves chemical deicers that are used on concrete pavements. The project initially involved writing a standard, but after its review it was determined that further research regarding de-icing chemicals was necessary. A complete analysis of different materials is currently being completed, which will result in a decision of the best product to use. This project has allowed me to use skills that I learned in my mechanical design classes relating to the five-step engineering problem solving method and decision making.

I am also currently working on a project that pertains to convenience store buildings. I am completing an investigation regarding the cost savings expected regarding lumber, masonry piers, foundation cell grout, and bond beams. Each aspect is a mini project within itself. Since this project involves the civil aspect of engineering (outside of my major), it has been slightly challenging for me to understand all the structural features of the building, but with guidance from the EiR, I have been able to continue working on the project. 
Overall, I feel that my experience has been beneficial. Not only am I gaining valuable work experience in my field of study, but I am learning important lessons in life such as time management, patience, communication, and teamwork skills that will be helpful to me after I graduation. I would highly recommend the EiR program to any student engineer.

\section{Matt Launsbach: Senior Mechanical Engineering student at Ohio Northern University.}

During my final year at ONU I have had the opportunity to be a full time student as well as a part time Co-op employee of Marathon Ashland Petroleum in the ONU EiR program. This program allows students to work approximately 15 hours each week on meaningful projects that provide a wide range of engineering experience. The task of working while attending school full time is a challenge, but the flexible work hours make it manageable. Work assignments and progress is overseen by a mentor who works closely with us and is always willing to help answer any questions that arise. This position has been a great asset in furthering my education and has given me the opportunity to apply what I have learned in the classroom and build from the new experiences and challenges found in the business world.

The main project that I have been assigned during my term at MAP has been to determine a means of calculating the flow rate capability of both new service stations and those already in use. While working on this project during the fall quarter, I was also taking a fluid dynamics course. The project and the material covered in the course complimented each other and I was able to apply many aspects of what I was learning in class to my calculations at work. My professor had also done similar work and proved to be an excellent resource for any questions that I had and gave me a great deal of additional help outside of the material covered in the course. I have also been working with several suppliers in this project, which has greatly improved my communication skills and my ability to work with other companies to gather information and resources. I have taken part in several business meetings in the MAP offices in Findlay, $\mathrm{OH}$ and had the opportunity to give a presentation of my findings and recommendations for future company direction.

I have had several other Co-op experiences at other large companies, but none have provided me such a meaningful and educational experience. Being able to apply what I was learning in the classroom, while also having access to the expertise of ONU professors and my mentors at MAP, has made this program one of the best experiences a young engineer could have.

Ryan Korkos: Senior electrical engineering student at Ohio Northern University.

Although I have worked in the EiR program this year, I have also worked for the past 4 years in MAP's Co-op program, where I have gained "real world" experience in engineering design and project management. This year in the EiR program has been no exception, as I have continued to learn new aspects of the petroleum industry and the engineering profession. 
In the EiR program this year, I have had the opportunity to work on projects that relate to many of the classes that I have taken throughout my experience at ONU. My main concentration in the EiR program has been on a project to develop a standard on electrical surge protection that will be used in many areas within MAP. This project has involved a substantial amount of research, as well as, working together with a group of experienced engineers, electrical technicians, and outside vendors to gather reliable information concerning surge protection equipment and industry standards. I also was given the responsibility to close-out a pipeline project that was functionally completed last summer. This project consisted of making site visits to the construction location in Lima, Ohio, and updating mechanical and electrical drawings of the site. Another responsibility related to the pipeline project was to make sure that all invoices were paid on time, and to keep track of the project's budget.

The EiR program is a unique opportunity to gain valuable work experience in the engineering field while taking classes at ONU. The projects assigned to students in the EiR program build and expand upon what is being taught in the classroom. Not only is it rewarding to put classroom knowledge to work, it is also advantageous to have engineering work experience in your background, when searching for a full-time job. Being a part of the EiR program does demand a great amount of discipline and hard work, while at the same time, I have been able to hone my time management skills. In my opinion, the benefits of working in the EiR program far outweigh the extra effort that is required. I am extremely grateful for my opportunity to work in the MAP/ONU EiR program and would strongly encourage any engineering student to consider this option.

\section{COMMENTS FROM THE DEAN OF ENGINEERING}

The Engineer in Residence program provides a win, win, win outcome for all three constituents. Ohio Northern University has been able to substantiate its relationship with a major corporation; Marathon Ashland Petroleum LLC has received significant engineering work product, and identified potential permanent employees; and most importantly, students have secured valuable real world experience and earnings which help them with their educational expenses. The value of the program in enabling students to practice engineering while they are still undergraduate students is very apparent. The remuneration they receive for their work provides significant income, without incurring the housing and subsistence costs associated with a conventional co-op program.

Engineering classes are enhanced by the invited presentations, discussions, and other activities that make it possible for the engineer in residence to bring workplace issues into the classroom. During the last year of the EiR office worked on more than 40 projects requiring in excess of 1900 hours of engineering work effort. This program represents one outcome of our efforts to produce a new generation of renaissance engineer with enhanced skills - the "industry-ready" engineer. 